\title{
Reflexões sobre o consumo consciente voltadas para o desenvolvimento sustentável
}

\author{
Reflections on conscious consumption targeted towards sustainable development
}

\author{
Josyane Mansano ${ }^{1}$ \\ Gisele Lopes de Oliveira ${ }^{2}$
}

\begin{abstract}
Resumo
Face ao consumo desacelerado em tempos hodiernos, o equilíbrio ambiental face ao consumidor moderno passa a ser tema preocupante. Saber a exata ponderação entre os princípios socioambientais e os afetos ao desenvolvimento sustentável é o grande desafio para o reconhecimento cada vez mais preciso de uma responsabilização pós-consumo. A logística sustentável vem como alternativa para esse impasse, por meio do consumo consciente, o qual perfaz um ciclo da produção, consumo, descarte, reciclagem. Nesse sentido, partindo de instrumentos de conscientização socioambiental, políticas públicas, e a inserção de toda a coletividade, têm como propósito assegurar qualidade de vida às futuras gerações.
\end{abstract}

Palavras Chave: Consumo consciente; Pós-consumo; Meio ambiente; Sustentabilidade.

\begin{abstract}
Face the consumption slowed in today's world, the environmental balance vis-à-vis the modern consumer is a concern. Knowing the exact weighting between social and environmental principles and the affections to sustainable development is the great challenge for recognising increasingly needs a post-consumer accountability. Sustainable logistics comes as an alternative to this impasse through conscious consumption, which makes a cycle of production, consumption, disposal, recycling. In this sense, environmental awareness, instruments with public policies, and the insertion of the whole collectivity, the purpose of ensuring quality of life for future generations.
\end{abstract}

Keywords: Conscious consumption; Post-consumer; Environment; Sustainability.

\footnotetext{
${ }^{1}$ Mestranda na Universidade de Marília UNIMAR - SP. Especialista em Direito Civil e Processo Civil - Instituto Paranaense de Ensino Maringá - PR. Advogada. jo271002@ hotmail.com.

2 Mestranda na Universidade de Marília UNIMAR - SP. giseleoliveira@ hotmail.com.
} 


\section{Introdução}

O consumo é um poder que temos nas mãos para mudar o estado das coisas. Mas não é só ao nível individual o desafio: as mais poderosas forças econômicas do mundo globalizado, as grandes empresas, têm de obedecer a uma linha ética se quiserem perdurar - a responsabilidade social empresarial não pode ser apenas uma técnica de marketing, como consumidores com alternativas de compra. Exige-se que seja posta em prática em todas as áreas de atuação das empresas.

Quando se compra qualquer produto, para além de satisfazer um desejo ou uma necessidade, participa-se economicamente no processo de produção desse produto: são os, consumidores, o último elo da cadeia. 0 consumo responsável leva a que se informe sobre 0 processo, para avaliar se quer ou não colaborar com ele. Além da qualidade pode-se ter em conta fatores ambientais e sociais, implicados em cada produto/produção. 0 consumo consciente consiste em ter em conta estas repercussões no momento de fazer diferentes opções de consumo.

Para ser agentes de mudança na erradicação dos problemas e desequilíbrios originados por esta sociedade de consumo globalizada, deve-se em primeiro lugar fazer a mudança no quotidiano, procurando atingir uma mudança global de comportamentos.

Não se deve resumir a uma declaração de intenções que perde impacto no dia-adia.

O consumo consciente não é uma utopia, tem de ser uma prática continuada.

Como não se pode mudar tudo e todos ao mesmo tempo, é preciso estabelecer prioridades e compreender o porquê da sua importância.

No campo das escolhas de compra do consumidor, a variedade de produtos e de alternativas já permite fazer escolhas deliberadas contra as empresas com práticas reprováveis.

Cada vez mais as empresas, nomeadamente os grandes gigantes econômicos, estão a reagir às exigências de ordem ética (sejam questões sociais e laborais, ambientais ou dos direitos dos animais) e compreendem que 0 consumidor e as suas reivindicações fazem também parte das suas opções empresariais. Nenhuma empresa quer perder o apoio dos principais destinatários dos seus produtos ou serviços. 
Enquanto peças-chave de todo o processo econômico, são os consumidores que tem o poder de confrontar os poderes instituídos, seja o poder econômico das grandes empresas, o poder político ou as instituições locais.

Para, além disso, todos têm algum acesso aos meios enquanto cidadãos e encontram apoio nas organizações que trabalham na área do desenvolvimento, da defesa do consumidor, dos direitos humanos ou do ambiente.

É nesta seara, na busca de um consumo sustentável, que se quer refletir sobre o ciclo do consumo.

0 Código de Defesa do Consumidor neste âmbito traz importantes alternativas para serem corroboradas na temática consumo e sustentabilidade, inclusive punindo fornecedores, produtores, importadores quando da colocação no mercado de produtos que na sua fabricação e manuseio possam ser vindos de praticas ecologicamente insustentáveis.

\section{Direito ambiental e direito econômico}

No intuito de entender a relação entre economia e meio ambiente é necessário e importante esclarecer o significado da relação entre o homem e a natureza através do trabalho. Essa natureza sempre existiu, contudo, com o advento do capitalismo, esta relação sofre uma profunda transformação. A lógica do lucro faz do homem e da natureza fontes de seu contínuo e crescente crescimento e reprodução. Transformados em forças produtivas, os meios de produção modernos não mais servem apenas de caminhos para retirar da natureza os meios de subsistência humana, passando a ser utilizados intensivamente para produzir os excedentes apropriados, na forma do lucro, pelo capital.

É sob essa estrutura que aparece a relação entre economia e meio ambiente. A questão do meio ambiente - a ecologia -, não pode ser abordada ou compreendida sem a vinculação com o regime capitalista de produção.

Tanto a agricultura explorada sob a forma capitalista como a indústria, em seu processo de crescimento e de concentração, participam da busca incessante de lucros desencadeando e intensificando, para tanto, métodos deletérios à natureza onde atuam.

A atual capacidade de intervenção nos ecossistemas, proporcionada pela tecnologia, não tem precedentes na história humana e remete a uma dura crítica aos modelos econômicos e às bases tecnológicas da produção além de, pela primeira vez, 
questionar "modelos de vida" que durante décadas serviram de exemplo de modernidade e desenvolvimento, mas que hoje é alvo de críticas consistentes pelo seu consumismo desenfreado e por - a altos custos - privilegiar uma pequena parte da população apenas.

Tratar do meio ambiente isoladamente, sem sua conexão com a economia de base capitalista, é mesmo que navegar na superfície dos fenômenos sem atingir sua essência.

O Direito das relações de consumo enquadra-se neste cenário regulatório e visa, precipuamente, coibir o abuso do poder econômico e corrigir assimetrias de informação. Tem-se ainda, que inevitavelmente, as soluções dos percalços ambientais passam por uma mudança nos valores de compreensão do mundo, cabendo ao direito, amenizar os transtornos ecológicos com a utilização dos recursos de que dispõe, sejam coercitivos ou educativos (DANTAS, 2010, p. 18).

Não à toa, muito antes de se cogitar a promulgação de um Código específico para a proteção das relações de consumo, Comparato (1978, p. 473) já considerava a proteção do consumidor como um importante capítulo do Direito econômico.

Conforme conceitua Derani (2008, p. 37):

Direito econômico é a normatização da política econômica como meio de dirigir, implementar, organizar e coordenar práticas econômicas, tendo em vista uma finalidade ou várias e procurando compatibilizar fins conflituosos dentro de uma orientação macroeconômica.

E ainda arremata: “E uma política econômica conseqüente não ignora a necessidade de uma política de proteção dos recursos naturais. Para isto, a economia deve voltar aos seus pressupostos sociais e abandonar qualquer pretensão por uma ciência exata."

As condições da modernidade impõem uma mudança na regulação econômica, da antiga lógica da imputação para a regulação apoiada na macrológica do Direito Econômico, finalística e reflexivamente voltada à realização do Desenvolvimento Sustentável definido na Constituição.

O futuro da Terra como um pequeno e limitado de uma humanidade que não para de crescer, dos ecossistemas praticamente esgotados pelos processos industrialistas parece desolador. De pessoas cada vez mais angustiadas com relação ao futuro do planeta e, conseqüentemente, com seu próprio futuro, e de outras que ainda sonham com o "jeito americano de viver", trabalhando arduamente para, pura e simplesmente, conseguir manter 
alto o nível de consumo. E todas elas sendo governadas e lideradas por pessoas cujo objetivo real é o poder, o lucro imediato, camuflado em seus discursos comoventes em prol de um mundo melhor.

Posto isto, a degradação ambiental criou novas necessidade e novos significados para o Direito, que passou a buscar influir sobre a realidade com vistas a solucionar a questão que the é apresentada.

\section{Consumo e sustentabilidade}

A atual sociedade de consumo vive momentos de grande discussão e reflexão. Sabemos que é preciso repensar os atuais padrões de consumo e sua interferência, direta, no meio ambiente. 0 consumidor deve ter consciência da sua importância nas transformações econômicas, sociais e políticas.

Os recursos do mundo estão escassos, uma vez que são consumidos de forma desordenada e sem se projetar a sua permanência no futuro. Atualmente, a sociedade consume 0 equivalente a 1,25 terras, o que significa que estão consumindo além da capacidade do planeta de produzir e renovar recursos naturais.

A solução para esse consumo desenfreado é a adoção de conceitos e princípios de sustentabilidade. Sustentabilidade nada mais é que o desenvolvimento de ações capazes de satisfazer as necessidades da sociedade sem prejudicar o meio ambiente e sem tirar a oportunidade das gerações futuras em satisfazer as suas.

Atualmente, as discussões correlatas encontram-se bastante difundidas, alcançando o cotidiano do cidadão comum e os dos mais diversos ramos do conhecimento. Partindo da conscientização de cada indivíduo da sociedade, tem-se a priorização da disseminação do conceito de consumo consciente. Pois, adquirindo a consciência sobre o que se consome 0 cidadão pode optar por estimular que o mercado, de modo geral, se adapte aos princípios sustentáveis, uma vez que os consumidores ditam o comportamento do mercado.

Com a Constituição Federal brasileira muito se evoluiu na tentativa de proteção dos direitos sociais. Suas idéias preambulares, preceituadas no artigo $1^{\circ}$ serão efetivadas ao congregar-se a proteção de conceitos como dignidade da pessoa humana, livre iniciativa e meio ambiente em um só Estado social e democrático. 
Contudo, congregar ao mesmo tempo livre iniciativa da ordem econômica e a proteção do meio ambiente ecologicamente equilibrado como bem coletivo é trabalho árduo. Para tanto, precisamos buscar um equilíbrio entre o uso e a proteção dos recursos naturais, exigindo-se uma racionalidade que respeite os limites impostos pela natureza.

Desta forma, os fundamentos constitucionais indicam uma utilização baseada na sustentabilidade, que nada mais é do que adquirir, utilizar e descartar produtos e serviços com respeito ao meio ambiente e à dignidade da pessoa humana.

Temos que, a situação degradante por que passa nosso meio ambiente está intimamente relacionada ao modelo de desenvolvimento capitalista adotado. Nosso modelo de desenvolvimento está baseado no consumo. Quanto mais consumo, mais produção e, conseqüentemente, mais lucro.

Os valores sociais estão esquecidos, de modo a fazer afirmar que o sucesso do ser humano é medido por aquilo que ele consome.

Durante décadas afirmou-se que a degradação ambiental era resultado do malfadado processo produtivo. Só a partir da década de 90, intensificou-se a percepção de que os problemas ambientais estariam relacionados aos atuais padrões de consumo, o que gerou uma nova posição dentro do ambientalismo.

Para Portilho (2005, p. 39), a autora entende que a redefinição teria se dado a partir de dois deslocamentos discursivos da definição da questão ambiental: do aumento populacional (principalmente no hemisfério sul) para o modelo de produção das sociedades afluentes (especialmente do hemisfério norte); e mais tarde, da preocupação com os problemas ambientais relacionados ao consumo e aos estilos de vida propriamente ditos.

A Agenda XXI, ao abordar o tema "Mudança de Padrões de Consumo", admite que as principais causas da deterio ração do meio ambiente estão nos padrões insustentáveis de produção e consumo e nos impactos produzidos pela pobreza nos países em desenvolvimento. Reconhece que, em determinadas partes do mundo, os padrões de consumo são muito altos e que existe um amplo segmento da sociedade que não é atendido em suas necessidades básicas. Referido documento, propõe uma mudança comportamental na forma de consumir e produzir. Propõe que os governos devem estimular grupos de consumidores, indivíduos e famílias através da "[...]... oferta de informações sobre as 
conseqüências das opções e comportamentos de consumo, de modo a estimular a demanda e o uso de produtos ambientalmente sustentáveis." (Agenda XXI, capítulo 4)

0 documento ainda recomenda, um esforço conjunto entre governo, indústria e sociedade em geral, para reduzir a geração de resíduos e de produtos descartados.

Há uma grande dificuldade em se ajustar os atuais padrões de consumo para um estilo mais consciente e responsável, justamente porque o estilo de vida americanizado é não só apreciado, mas desejado pela maioria da população do planeta. A verdadeira sustentabilidade vai exigir que o mercado e o processo de produção e consumo sejam reformulados.

Portilho (2005, p. 109) afirma que:

movimentos sociais, como as chamadas Organizações de Defesa dos Consumidores, tradicionalmente preocupadas apenas com a proteção dos direitos do consumidor no mercado e 0 aumento da disponibilidade das suas opções de escolha começam a esboçar propostas de compatibilizar a defesa dos consumidores com a defesa do meio ambiente, lançando e participando de campanhas por um consumo menos predatório, somando esforços e se aproximando dos movimentos ambientalistas stritu sensu.

A busca por um desenvolvimento que seja realmente sustentável requer processos de produção e consumo, mais coerentes e racionais. A sociedade moderna é constantemente incentivada pela mídia e pelo próprio modo de vida urbano a um consumo desenfreado, com aquisição de produtos, em muitas oportunidades, supérfluos e descartáveis. 0 status da pessoa é medido pelo que a mesma consome. 0 consumidor é induzido ao descarte do produto do modelo anterior em prazo exíguo para comprar o do modelo novo que se, de um lado, fomenta a economia, de outro, importa no acréscimo na geração de resíduos. Na atual sociedade de consumo, o objetivo maior do homem é consumir tudo aquilo que lhe é permitido com o fruto do seu trabalho.

Segundo Portilho (2005, p. 67):

A abundância dos bens de consumo continuamente produzidos pelo sistema industrial é considerada, freqüentemente, um símbolo da performance bemsucedida das economias capitalistas modernas. No entanto, esta abundância passou a receber uma conotação negativa sendo objeto de críticas que consideram o consumismo um dos principais problemas das sociedades industriais modernas. A partir da construção da percepção de que os atuais padrões de consumo estão nas raízes da crise ambiental, a crítica ao consumismo passou a ser vista como uma contribuição para a construção de uma sociedade sustentável. 
O consumo em si não é problema, mas seus atuais padrões e efeitos refletem diretamente no meio ambiente e na esfera social. Segundo Feldmann (2007, p. 78):

O consumo é essencial para a vida humana, visto que cada um de nós é consumidor. 0 problema não é o consumo em si mesmo, mas os seus padrões e efeitos, no que se refere à conciliação de suas pressões sobre o meio ambiente e o atendimento das necessidades básicas da Humanidade. Para tanto, é necessário desenvolver melhor compreensão do papel do consumo na vida cotidiana das pessoas. De um lado, o consumo abre enormes oportunidades para 0 atendimento de necessidades individuais de alimentação, habitação, saneamento, instrução, energia, enfim, de bem-estar material, objetivando que as pessoas possam gozar de dignidade, auto-estima, respeito e outros valores fundamentais. Nesse sentido, o consumo contribui claramente para o desenvolvimento humano, quando aumenta suas capacidades, sem afetar adversamente o bem-estar coletivo, quando é tão favorável para as gerações futuras como para as presentes, quando respeita a capacidade de suporte do planeta e quando encoraja a emergência de comunidades dinâmicas e criativas. 0 consumo na vida contemporânea, entretanto, traz novas dinâmicas e a sua compreensão está longe de ser alcançada.

Contudo, com a informação adequada e consciência de que certos atos de consumo influem de maneira direta no meio ambiente, o consumidor pode fazer a diferença, mudando seus padrões de consumo, o que determinará mudanças em toda a cadeia produtiva. E, como salienta Sodré (1999, p. 32), "somando qualidade ambiental à qualidade do produto".

Não há dúvidas de que a atual sociedade de consumo está degradando o planeta, quer pelo abuso que se faz dos recursos naturais, quer pela produção excessiva de resíduos. Se o simples ato de consumir gera impacto ao meio ambiente, resta ao cidadão optar pelo melhor consumo, ou seja, aquele que cause o menor impacto na natureza.

Para isso, expressões como "consumo sustentável", "consumo consciente", "consumo responsável", "consumo solidário", dentre outros compatíveis, devem ser difundidos.

\section{A logística sustentável do consumidor moderno}

O consumidor moderno, consciente, reconhece em suas ações cotidianas o impacto que suas decisões de compra causam no mundo, podendo repercutir positivamente ou negativamente na sociedade. Isso acontece em dois momentos distintos, no ato da aquisição do produto e no ato de seu consumo, resultado da compra. 
A necessidade árdua de um consumo consciente traz enormes contribuições em nossa sociedade, tanto no presente, como no futuro. Quando um consumidor opta por adquirir um produto de uma empresa socialmente responsável ele está ajudando a manter a lógica do comércio justo, ou seja, privilegiando uma empresa que possui um engajamento social na produção e comercialização de seu produto. Caso o consumidor não faça essa opção, estará estimulando que as demais empresas, que não possuem uma preocupação de cunho ambiental, continuem praticando ações contra a sustentabilidade. Contudo, a atuação do consumidor consciente não se restringe apenas a escolher fabricantes de produtos sustentáveis, pois, vai desde a reflexão sobre a redução da quantidade de produtos que realmente necessita adquirir, até a reutilização ou reciclagem de produtos que muitas vezes eram considerados como lixo.

o consumidor consciente busca o equilíbrio entre a sua satisfação e a sustentabilidade, maximizando as conseqüências positivas deste ato não só para si mesmo, mas também para as relações sociais, a economia e a natureza. 0 consumidor consciente também busca disseminar o conceito e a prática do consumo consciente, fazendo que pequenos gestos realizados por um número muito grande de pessoas promovam grandes transformações.

O novo consumidor brasileiro, há algum tempo já vem difundindo a ideia dos atos sustentáveis assumidos pelas empresas da qual os mesmos são consumidores, procurando, via mídia social "on line", informações e detalhes sobre ações responsáveis desenvolvidas pelas companhias das quais é cliente.

Podemos ainda citar como uma nova visão do consumidor moderno, a responsabilidade pelo descarte de produtos e destinação final de resíduos, também conhecida como "responsabilidade pós-consumo", deve ser compartilhada entre todos os elos da cadeia produtiva. Não significa obrigar o consumidor a arcar com as despesas da destinação final dos resíduos, ao contrário, é com sua atitude preventiva, no sentido de escolher um produto ambientalmente adequado e optando por uma empresa ou marca que se preocupe com o meio ambiente, que o consumidor cumprirá seu papel e contribuirá para a melhoria da qualidade de vida na Terra. 
Contudo, para essa nova visão, o consumidor deve ser alvo de programas educacionais e de conscientização que lhe repassem informações claras, precisas e suficientes a ponto de influir em sua decisão de consumo.

O consumo sustentável, que nasce da mudança de atitude dos consumidores e da sociedade em geral, utiliza os recursos naturais para satisfazer as necessidades atuais, sem comprometer as necessidades e aspirações futuras.

O consumidor deve ser incentivado a fazer com que o seu ato de consumo seja também um ato de cidadania, ao escolher em que mundo quer viver. Cada pessoa deve escolher produtos e serviços que satisfaçam suas necessidades sem prejudicar o bem-estar da coletividade, seja ela atual ou futura.

Dar preferência a produtos de empresas que tem uma clara preocupação com 0 meio ambiente, não compactuar com a ilegalidade, não consumir de forma a prejudicar as gerações futuras, dar preferência às empresas que não exploram o trabalho infantil, reclamar os seus direitos, usar o poder de compra para defender o emprego no país adquirindo produtos nacionais, colaborar para reduzir a quantidade de lixo produzido, evitar o desperdício e a compra de produtos com embalagens inúteis ou que demorem a se decompor, dar preferência a materiais reciclados, saber identificar as empresas que são éticas em seu relacionamento com os consumidores, os trabalhadores, os fornecedores, a sociedade e o Poder Público, são algumas das ações do consumidor consciente, com o perfil do consumidor moderno. ${ }^{3}$

Percebe-se, cada vez mais, que os consumidores querem, além de bons produtos e serviços, fornecedores que estejam comprometidos com a melhoria da qualidade de vida da comunidade.

Quando percebe a existência de consciência social, o consumidor se identifica com a empresa sob o prisma do exercício da cidadania, criando vínculos de fidelidade difíceis de ocorrer com entidades que cultivam valores diferentes (M ELO NETO, 2001, p. 101).

Segundo o Instituto Brasileiro de Defesa do Consumidor - IDEC (2005, p. 59-62):

A atitude dos consumidores está mudando. Além do preço e qualidade, eles estão cada vez mais atentos a aspectos relacionados ao comportamento das empresas,

\footnotetext{
${ }^{3}$ INSTITUTO NACIONAL DE METROLOGIA, NORMALIZAÇÃO E QUALIDADE INDUSTRIAL. Consumo sustentável: Manual de educação. Brasília: Consumers International/M M A/MEC/IDEC, 2005, p. 59-62.
} 
como o respeito aos direitos humanos, trabal histas e dos consumidores; as normas de preservação ambiental; à ética na publicidade e nas práticas empresariais; a promoção do bem-estar social; etc. A transparência das empresas em relação a essas informações também passa a ser valorizada, tornando-se a principal ferramenta para o consumo consciente e cidadão.

De acordo com uma pesquisa realizada pelo Instituto Ethos, 31\% dos consumidores brasileiros prestigiaram ou puniram uma empresa com base em sua conduta social. Entre os identificados como "líderes de opinião", esse índice chega a 50\% e, entre os entrevistados com maior nível de escolaridade, $40 \%$ revelaram o mesmo comportamento. Para $51 \%$ dos consumidores, a ética dos negócios é um dos principais fatores para se avaliar uma empresa (ASHLEY, 2003, p. 71).

Embora seja a parte mais vulnerável na relação de consumo, em termos de preservação do meio ambiente, o consumidor tem grande poder, pois possui poder de escolha sobre os produtos e serviços à sua disposição no mercado.

Desta forma, temos que o consumidor moderno é aquele que busca a sustentabilidade nas suas ações junto ao mercado, ou seja, pauta-se pelo consumo de forma responsável frente à economia e sua relação direta com o meio ambiente.

\section{Busca pelo consumo consciente}

O mundo do consumo nesses tempos hodiernos é fruto da constante transformação da sociedade.

Essas mudanças na postura da sociedade com a inserção do consumo de massa desencadeado pela produção em série de bens de consumo a partir da Revolução Industrial, impulsionou o homem a criar cada vez mais objetos e a colocá-lo no mercado para que outros em mais outros viessem a adquiri-los.

Segundo Trigueiro (2005, p. 26), em entrevista com Helio Mattar, diretor presidente do Instituto Akatu ${ }^{4}$ pelo Consumo Consciente, exibida em dezembro ode 2004, no programa Almanaque, da Globo News, tem-se os seguintes dados:

\footnotetext{
${ }^{4} 0$ instituto Akatu é uma organização não-governamental, sem fins lucrativos, criada em 15 de marco (Dia mundial do Consumidor) de 2001, com a missão de educar, informar, sensibilizar, mobilizar e animar cidadãos para assimilar, em seus comportamentos e atitudes, o conceito e a pratica do consumo consciente.
} 
Hoje, $20 \%$ da população mundial realizam aproximadamente $86 \%$ do total das compras que são feitas no mundo. Pesquisei um relatório das Nações Unidas de 1998 que revela o seguinte: esses $20 \%$ da população conso mem $45 \%$ da carne e do peixe, $60 \%$ da energia, $75 \%$ das linhas telefônicas, $85 \%$ do papel e $90 \%$ dos veículos. Isso mostra que nos países ricos se concentra, hoje, a grande parcela do impacto do ato de consumo sobre a sociedade e o meio ambiente.

Assim, partindo da conscientização de cada indivíduo da sociedade, tem-se a priorização da disseminação do conceito de consumo consciente ${ }^{5}$. Pois, adquirindo a consciência sobre o que se consome o cidadão pode optar por estimular que o mercado, de modo geral, se adapte aos princípios sustentáveis, uma vez que os consumidores ditam o comportamento do mercado.

O conceito de consumo sustentável ${ }^{6}$, ou consumo consciente, está descrito em texto elaborado pela Comissão de Desenvolvimento Sustentável da Organização das Nações Unidas (CDC/ONU), e teve sua origem a partir da Resolução n. 153/1995, de alçada da Organização das Nações Unidas que delineou no campo do direito do consumidor uma nova formatação de apreciação das relações entre consumidores e os fornecedores dos mais variados tipos de produtos.

Vem daí, então que consumo consciente, significa consumir atento ao impacto que determinados produtos e serviços podem causar ao meio ambiente, evitando-os sempre que possível. Isto é, o consumidor consciente reconhece o impacto que suas decisões de compra causam, repercutindo positivamente ou negativamente na sociedade. Isso acontece em dois momentos: no ato da compra e no consumo do resultado dessa compra.

De que forma o consumo consciente contribui?

Quando um consumidor opta por adquirir um produto de uma empresa socialmente responsável ele está ajudando a manter a lógica do comércio justo. Caso ele

\footnotetext{
${ }^{5}$ Consumo consciente segundo a Agenda 21 pode ser entendido como: 0 recente surgimento, em muitos países, de um público consumidor mais consciente do ponto de vista ecológico, associado a um maior interesse, por parte de algumas indústrias, em fornecer bens de consumo mais saudáveis ambientalmente, constitui acontecimento significativo que deve ser estimulado. Os Governos e as organizações internacionais, juntamente com o setor privado, devem desenvolver critérios e metodologias de avaliação dos impactos sobre o meio ambiente e das exigências de recursos durante a totalidade dos processos e ao longo de todo o ciclo de vida dos produtos. Os resultados de tal avaliação devem ser transformados em indicadores claros para informação dos consumidores e das pessoas em posição de tomar decisões.

${ }^{6} 0$ tema consumo sustentável tem sido utilizado por diversas expressões. Nesse sentido, Portilho (2005, p. 110) esclarece que: "A questão do impacto ambiental do consumo foi definida, inicialmente, nos limites da noção "consumo verde" e um pouco mais tarde concentrou-se no chamado "consumo sustentável", alem de expressões similares que contribuem mais para confundir do que para enriquecer a discussão, tais como "consumo ético", "consumo responsável" e "consumo consciente"".
} 
não faça essa opção, está estimulando que esse fabricante ou fornecedor continue praticando ações contra a sustentabilidade.

Contudo, a atuação do consumidor consciente não se restringe apenas a escolher fabricantes de produtos sustentáveis, pois, vai desde a reflexão sobre a redução da quantidade de produtos que se necessita adquirir, economia de água e energia, por exemplo, até a reutilização ou reciclagem de produtos que muitas vezes eram considerados como lixo.

Ser um consumidor consciente envolve uma ação cotidiana, que requer uma mudança de hábito sobre as novas práticas que devem ser adotadas.

Ser um consumidor consciente é saber que suas ações individuais são capazes de promover transformações no mundo

0 consumidor consciente precisa ter os pés no chão. Já se gastou mais do que seria permitido, ou seja, se está em débito com o futuro.

Assim para se discutir os problemas da sustentabilidade e da preservação ambiental, deve-se levar em conta que esse acerto precisa ser feito considerando um certo débito para com a vida. Um exemplo disso pode vir a partir do papel: um indivíduo consome duas árvores por ano. Se levar em consideração também o CO2, o indivíduo tem mais duas árvores por ano para acertar com a natureza. Então, cada indivíduo "consome" quatro árvores por ano. Na questão do papel, sabe-se que 40 quilos de papel é igual a uma árvore. Consome-se 80 quilos de papel per capita. Considerando esse débito, é só questionar quantos anos cada um tem e saber o quanto se está devendo. Essa conta é importantíssima até para um grupo familiar ${ }^{7}$ (M EDEIROS, p. 13,2007).

0 consumidor consciente busca o equilíbrio entre a sua satisfação pessoal e a sustentabilidade, maximizando as conseqüências positivas deste ato não só para si mesmo, mas também para as relações sociais, a economia e a natureza. 0 consumidor consciente também busca disseminar o conceito e a prática do consumo, fazendo com que pequenos gestos realizados por um número muito grande de pessoas promovam grandes transformações.

\footnotetext{
${ }^{7}$ Zuleica M edeiros é presidente do Instituto Terra, localizado em Florianópolis, Santa Catarina, e coordena pessoalmente o projeto Cidadania em Cadeia para o Direito do Futuro, que contribui para ressocialização dos detentos do Presídio Central da capital do Estado. Disponivel em: http://www.ecodebate.com.br/Consumo consciente, comércio justo e sustentabilidade. Entrevista especial com Zuleica Medeiros, 15/10/2007. Acesso em 02 de Nov. 2010.
} 
O consumo consciente pode ser praticado no dia-a-dia, por meio de gestos simples que levem em conta os impactos da compra, uso ou descarte de produtos ou serviços, ou pela escolha das empresas da qual comprar, em função de seu compromisso com 0 desenvolvimento sócio-ambiental. Assim, o consumo consciente é uma contribuição voluntária, cotidiana e solidária para garantir a sustentabilidade da vida no planeta.

Consumo consciente é não consumir? Não, é consumir diferente: escolhendo os impactos que se quer causar, é consumir solidariamente: buscando os impactos positivos para o bem estar da sociedade e do meio ambiente. É consumir sustentavelmente: contribuindo para que as próximas gerações se beneficiem do milagre da vida como conhecemos hoje no planeta.

O que se tem hoje é uma crise ambiental, e esta é fruto justamente do ímpeto humano na busca pelo lucro que é revestido na simplista idéia de bem-estar e sensação de felicidade que o consumo traz às pessoas pelo potencial de mensurabilidade do que se está adquirindo.

Considerando que o consumo é o grande propulsor da indústria e que na atual realidade pátria os fabricantes se limitam a colocar os produtos no mercado, não se importando com a sua destinação final, importa mencionar que para se delinear a responsabilidade pós-consumo dos fabricantes de embalagens, necessário fazer algumas considerações sobre a natureza e o liame jurídico existentes na relação de consumo.

Nesse sentido, Agenda $21^{8}$ dispõe acertadamente:

4.15. A fim de que se atinjam os objetivos de qualidade ambiental e desenvolvimento sustentável será necessário eficiência na produção e mudanças nos padrões de consumo para dar prioridade ao uso ótimo dos recursos e à redução do desperdício ao mínimo. Em muitos casos, isso irá exigir uma reorientação dos atuais padrões de produção e consumo, desenvolvidos pelas sociedades industriais e por sua vez imitados em boa parte do mundo.

\footnotetext{
${ }^{8}$ A Agenda 21 é o principal resultado da Conferência das Nações Unidas para o Meio Ambiente e 0 Desenvolvimento - UNCED/Rio-92. Este documento foi discutido e negociado exaustivamente entre as centenas de países ali presentes, sendo, portanto um produto diplomático contendo consensos e propostas. Agenda 21 é um documento estratégico, um programa de ações abrangente para ser adotado global, nacional e localmente, visando fomentar em escala planetária, a partir do século XXI, um novo modelo de desenvolvimento que modifique os padrões de consumo e produção de forma a reduzir as pressões ambientais e atender as necessidades básicas da humanidade. A este novo padrão, que concilia justiça social, eficiência econômica e equilíbrio ambiental, convencionou-se chamar de Desenvolvimento Sustentável.
} 
Disso pressupõe, que uma relação de consumo é evidência a partir da existência das figuras do fabricante, do fornecedor ou comerciante e do consumidor. Assim, se completa, com a presença do consumidor.

Dessa forma, pode-se dizer que é a partir da educação ambiental que se partirá para uma inserção da conscientização ambiental. Este princípio, segundo Fiorillo (2001, p. 39) é resultante do principio da tutela ambiental, possuindo as seguintes significações:

Educar ambientalmente significa: a) reduzir os custos ambientais, à medida que a população atuar como guardião do meio ambiente, b) efetivar o princípio da prevenção; c) fixar a idéia de consciência ecológica, que buscara sempre a utilização de tecnologias limpas; d) incentivar a realização do princípio da solidariedade, no exato sentido que perceberá que o meio ambiente é único, indivisível e de titulares indetermináveis, devendo ser justa e distributivamente acessível a todos; e) efetuar o princípio da participação, entre outras finalidades.

Assim, o que se espera é que tudo o que já vem sendo discutido desde a Conferência do Rio em 1992, bem como do que prescreve a agenda 21, possa ser praticadas com eficácia. A agenda 21 trata dos padrões de consumo, introduzindo uma estratégia multifacetada, onde prioriza a redução do desperdício dos recursos finitos na natureza, bem como do consumo dos mesmos ${ }^{9}$.

\section{Relações entre responsabilização pós-consumo e a formação da consciência socioambiental}

A responsabilidade pós-consumo revela a importância sumária de fazer com que os fabricantes passem a buscar nos meios de produção mecanismos coerentes com relação à proteção do meio ambiente.

\footnotetext{
${ }^{9}$ Agendo 21: Cap. 4 - A: 4.5. Especial atenção deve ser dedicada à demanda de recursos naturais gerada pelo consumo insustentável, bem como ao uso eficiente desses recursos, coerentemente com o objetivo de reduzir ao mínimo o esgotamento desses recursos e de reduzir a poluição. Embora em determinadas partes do mundo os padrões de consumo sejam muito altos, as necessidades básicas do consumidor de um amplo segmento da humanidade não estão sendo atendidas. Isso se traduz em demanda excessiva e estilos de vida insustentáveis nos segmentos mais ricos, que exercem imensas pressões sobre o meio ambiente. Enquanto isso os segmentos mais pobres não têm condições de ser atendidos em suas necessidades de alimentação, saúde, moradia e educação. A mudança dos padrões de consumo exigirá uma estratégia multifacetada centrada na demanda, no atendimento das necessidades básicas dos pobres e na redução do desperdício e do uso de recursos finitos no processo de produção.
} 
Para a consecução da responsabilização pós-consumo, deve-se ter presente a participação do consumidor ${ }^{10}$, para exigir que os fabricantes venham a adotar medidas ambientalmente corretas e preocupem-se com os riscos ambientais negativos decorrentes da utilização de matérias-primas, fazendo isso através da utilização da responsabilidade socioambiental.

Todos os instrumentos necessários á efetivação da responsabilidade socioambiental estão focados no poder que detém o consumidor em exigir dos fabricantes mudanças com vistas á produção limpa e sustentável, preocupados com as externalidades do meio, com vistas a sociedade de risco que todo o resíduo gerado pelo consumo inconsciente pode vir a gerar.

Assim, pode-se dizer que o consumidor é detentor do direito de escolha e pode efetuar o boicote da aquisição de produtos que sejam ambientalmente nocivos ou que os fabricantes não se responsabilizem é pela destinação após o consumo, através de postos de coleta, a exemplo do que dispõe a Política Nacional de Resíduos Sólidos, Lei no 12.305.

0 fabricante que agir desta maneira, vai fazer com que a responsabilidade socioambiental esteja presente em suas práticas, angariando resultados positivos à sua empresa.

A responsabilização pós-consumo integra a agenda de discussões entre questão ambiental e consumo, fazendo emergir o que a doutrina denomina de relação de consumo sustentável, principalmente sob o argumento da escassez dos recursos naturais existentes no planeta (SPINDOLA, 2001, p. 209).

Como fazer um pós-consumo responsável?

Os movimentos da sociedade civil já há muito apregoam princípios básicos para 0 comportamento em todas as áreas da vida e do consumo, um exemplo disso parte da chamada Educação para o Desenvolvimento: a política dos 3R's: Reduzir o consumo; Reutilizar o mais possível os produtos e Reciclar no final da vida útil vai sendo atualizado e agrupa novos R's. Mas pôr em prática os 3R's nem sempre é fácil, vai-se aprendendo formas diferentes de consumir e reinventando a ação de consumidores conscientes. É que as boas práticas têm de se estender à maioria da sociedade e do seu funcionamento.

\footnotetext{
${ }^{10}$ Segundo o Código de Defesa do Consumidor, define-se consumidor como: Art. $2^{\circ}$ Consumidor é to da pessoa física ou jurídica que adquire ou utiliza produto ou serviço como destinatário final.
} 


\section{o Código de Defesa do Consumidor e a proteção do meio ambiente}

Há uma grande preocupação com o contexto da proteção ambiental no Código de Proteção e Defesa do Consumidor, o qual muito embora em momento algum cite explicitamente a proteção direta ao meio ambiente, se esclareça que a proteção ambiental aparece de modo implícito e pela interpretação dos objetivos da Política Nacional de Proteção ao Consumidor que faz menção as expressões dignidade, saúde, segurança, e melhora da qualidade de vida do consumidor.

Dessa forma necessário se faz a análise do direito ambiental e do direito do consumidor, enquanto geração de direito, porquanto que atualmente esses dois ramos do direito integram o que comumente a doutrina trabalha como sendo "novos direitos" (LORENZETTI, 1998).

Assim, ao estabelecer especificamente no caput do artigo $4{ }^{\text {0 }}{ }^{11}$ do Código de Proteção e Defesa do Consumidor os objetivos da política nacional de proteção ao consumidor, o legislador garantiu a proteção e o respeito á saúde e a melhora da qualidade de vida, reconheceu implicitamente a proteção do meio ambiente. 0 Artigo 4으, caput do CDC, ao estabelecer os objetivos da Política Nacional de Proteção ao Consumidor, traz na expressão "melhora da qualidade de vida" uma questão central.

\footnotetext{
${ }^{11}$ Estabelece 0 Código de Proteção e Defesa do Consumidor em seu artigo 40 não somente as bases e diretrizes para a política de defesa do consumidor, como também os princípios respeitantes ao direito do consumidor, prescrevendo que: Art. 4ํ A Política Nacional das Relações de Consumo tem por objetivo 0 atendimento das necessidades dos consumidores, o respeito à sua dignidade, saúde e segurança, a proteção de seus interesses econômicos, a melhoria da sua qualidade de vida, bem como a transparência e harmonia das relações de consumo, atendidos os seguintes princípios: I - reconhecimento da vulnerabilidade do consumidor no mercado de consumo; II - ação governamental no sentido de proteger efetivamente o consumidor: a) por iniciativa direta; b) por incentivos à criação e desenvolvimento de associações representativas; c) pela presença do Estado no mercado de consumo; d) pela garantia dos produtos e serviços com padrões adequados de qualidade, segurança, durabilidade e desempenho.III - harmonização dos interesses dos participantes das relações de consumo e compatibilização da proteção do consumidor com a necessidade de desenvolvimento econômico e tecnológico, de modo a viabilizar os princípios nos quais se funda a ordem econômica (art. 170, da Constituição Federal), sempre com base na boa-fé e equilíbrio nas relações entre consumidores e fornecedores; IV - educação e informação de fornecedores e consumidores, quanto aos seus direitos e deveres, com vistas à melhoria do mercado de consumo; $V$ - incentivo à criação pelos fornecedores de meios eficientes de controle de qualidade e segurança de produtos e serviços, assim como de mecanismos alternativos de solução de conflitos de consumo;

$\mathrm{VI}$ - coibição e repressão eficientes de todos os abusos praticados no mercado de consumo, inclusive a concorrência desleal e utilização indevida de inventos e criações industriais das marcas e nomes comerciais e signos distintivos, que possam causar prejuízos aos consumidores; VII - racionalização e melhoria dos serviços públicos; VIII - estudo constante das modificações do mercado de consumo.
} 
Isso porque, a proteção ambiental também se inclui neste aspecto, principalmente porque um meio ambiente ecologicamente equilibrado passa também por esta melhora da qualidade de vida das pessoas.

Nesse entendimento, Almeida (2002, p. 480), esclarece a relação de proteção existente no direito do consumidor ao meio ambiente, defendendo que: "direito a um meio ambiente saudável - na medida em que o equilíbrio ecológico reflete a melhoria da qualidade de vida do consumidor, de nada adiantaria cuidar dele isoladamente enquanto 0 ambiente que o cerca se deteriora e traz efeitos ainda mais movidos à sua saúde."

Não bastasse a ligação necessária entre a melhoria na qualidade de vida do consumidor e a relação com o meio ambiente saudável, deve-se atentar também que o fato de não ter o legislador inserido especificamente no rol de direitos básicos do consumidor expressamente este direito, não significa que 0 tenha negado, posto que esse direito foi constitucionalmente assegurado no artigo $225^{12}$, da Constituição Federal de 1988.

Outra norma que estabelece a proteção ambiental dentro do conteúdo do CDC é 0 texto do artigo $6^{0^{13}}$, inciso I. Esta norma ao instituir os direitos básicos dos consumidores também de modo implícito respalda a proteção ambiental.

Outra norma que guarda relação com a proteção ambiental e que está implicitamente tratada no CDC, diz respeito ao artigo 51, incisos III, IV e incisos ${ }^{14}$.

A relação destes dispositivos com a proteção ambiental são praticamente as bases para a responsabilização pós-consumo, conforme já analisado anteriormente.

Analisada a correlação existente entre as disposições de direito material constantes do CDC, faz-se necessária a abordagem dos meios processuais inseridos na referida

\footnotetext{
${ }^{12}$ Art. 225. Todos têm direito ao meio ambiente ecologicamente equilibrado, bem de uso comum do povo e essencial à sadia qualidade de vida, impondo-se ao Poder Público e à coletividade o dever de defendê-lo e preservá- lo para as presentes e futuras gerações.

${ }^{13}$ Estabelece 0 artigo 60 do CDC, que: Art. 60 São direitos básicos do consumidor:

I - a proteção da vida, saúde e segurança contra os riscos provocados por práticas no fornecimento de produtos e serviços considerados perigosos ou nocivos;

${ }^{14}$ Dispõe as regras do artigo 51 . São nulas de pleno direito, entre outras, as cláusulas contratuais relativas ao fornecimento de produtos e serviços que: III - transfiram responsabilidades a terceiros; IV - estabeleçam obrigações consideradas iníquas, abusivas, que coloquem o consumidor em desvantagem exagerada, ou seja, incompatíveis com a boa-fé ou a eqüidade; § 1 ㅇ Presume-se exagerada, entre outros casos, a vontade que: I ofende os princípios fundamentais do sistema jurídico a que pertence; II - restringe direitos ou obrigações fundamentais inerentes à natureza do contrato, de tal modo a ameaçar seu objeto ou equilíbrio contratual; III se mostra excessivamente onerosa para o consumidor, considerando-se a natureza e conteúdo do contrato, 0 interesse das partes e outras circunstâncias peculiares ao caso.
} 
legislação, que indissociavelmente possuem aplicação na proteção ao ambiente natural. Dessa forma, os meios processuais utilizados na defesa dos interesses tanto dos consumidores quanto da proteção do meio ambiente é a Ação Civil Pública, a qual foi instituída no ordenamento jurídico pátrio através da Lei n. 7347/85.

No que se refere á inter-relação entre a proteção ao meio ambiente e a proteção ao consumidor, enquanto direito transindividuais e decorrentes da lei da Ação Civil Pública, Mancuso (1997, p. 40) assevera que:

É sempre importante não perder de vista que é por forca de lei que esse interesse metaindividuais forma libertados do "limbo jurídico" em que se encontravam, para se exteriorizarem como posições socialmente relevantes, dignas, portanto, de tutela jurisdicional diferenciada; no caso, a que se faz através das ações coletivas, em sentido largo. Logo, se num caso concreto constata-se que o interesse objetivado é um daqueles já nomeadamente "normatizados" ou então é outro interesse relevante em sua essências (difusos, coletivos em sentido estrito u em sua exteriorização (individuais homogêneos), não se poderá denegar a tutela através da ação civil púbica ajuizável por qualquer dos legitimados.

Portanto a proteção ao consumidor e ao meio ambiente denota sua importante relevância enquanto objetos de tutela, posto que intimamente relacionados em vários aspectos, conforme abordados.

É a partir de atitudes socioambientais sustentáveis que pode-se concretizar o que já vem exposto em legislação a muito tempo discutida, e que necessitam de atitudes conscientes por parte dos consumidores para que o efeito sustentável possa ter sucesso e eficácia.

\section{Conclusão}

Não há duvida de que a atual sociedade de consumo está degradando o planeta, quer pelo abuso que se faz dos recursos naturais, quer pela produção excessiva de resíduos. Se o simples ato de consumir gera impacto no meio ambiente, resta ao cidadão optar pelo "melhor" consumo, ou seja, aquele que cause o menor impacto na natureza.

Para isso, expressões como "consumo sustentável", "consumo consciente", "consumo responsável", "consumo solidário", dentre outros compatíveis, devem ser difundidos. Mas, não podem ser apenas tratados como teoria, devem ser aprimorados e colocados à população, no sentido de informação, educação, conhecimento. A aplicação 
desses conceitos no cotidiano das pessoas tem o poder de transformar comportamentos e atitudes. Uma sociedade esclarecida e conhecedora dos reais impactos ambientais tem o discernimento para escolher um produto que seja ecologicamente correto e uma empresa que seja social e ambientalmente responsável.

\section{Referências}

ALM EIDA, João Batista de. A proteção jurídica do consumidor. 3. ed. São Paulo: Saraiva, 2002.

ASHLEY, Patrícia Almeida (Coord.). Ética e responsabilidade social nos negócios. São Paulo: Saraiva, 2003.

BRASIL. Constituição (1988). Constituição da Republica Federativa do Brasil. Disponível em: বttp//www.planalto.gov.br>. Acesso em: 2 nov. 2010.

COM PARATO, Fábio Konder. Ensaios e pareceres de direito empresarial. Rio de Janeiro: Forense, 1978.

BRASIL. Código de Defesa Consumidor. Dispõe sobre a proteção do consumidor e dá outras providências. Disponível em: ‘ttp://www.planalto.gov.br/ccivil_03/Leis/L8078.htm>. Acesso em: 2 nov. 2010.

DANTAS, Marcelo Buzagio; LEITE, José Rubens M orato Leite (Coord.). Aspectos processuais do direito ambiental. 3. ed. Rio de Janeiro: Forense Universitária, 2010.

DERANI, Cristiane. Direito ambiental econômico. 3. ed. São Paulo: Saraiva, 2008.

INSTITUTO BRASILEIRO DE DEFESA DO CONSUM IDOR. Guia de Responsabilidade Social para o consumidor. São Paulo, 2005.

INSTITUTO NACIONAL DE METROLOGIA, NORM ALIZAÇÃO E QUALIDADE INDUSTRIAL. Consumo sustentável: manual de educação. Brasília: Consumers International / M M A/ MEC/IDEC, 2005.

M ANCUSO, Rodolfo de Camargo . Interesses difusos e coletivos. Revista de Direito do Consumidor. São Paulo, v. 1, n. 22, p. 1, 1997.

M ELO NETO, Francisco Paulo; FROES, César. Responsabilidade social e cidadania empresarial: a administração do terceiro setor. 2. ed. Rio de Janeiro: Qualitymark, 2001.

LORENZETTI, Ricardo Luiz. Fundamentos do direito privado. São Paulo: Revista dos Tribunais, 1998.

M EDEIROS, Zuleica. Consumo consciente, comércio justo e sustentabilidade: entrevista especial com Zuleica Medeiros. 2007. Disponível em: 〈ttp://www.ecodebate.com.br/>. Acesso em: 2 nov. 2010. 
M ELO NETO, Francisco Paulo; FROES, César. Responsabilidade social e cidadania empresarial: a administração do terceiro setor. 2. ed. Rio de Janeiro: Qualitymark, 2001

MILARÉ, Edis. Agenda 21: a cartilha do desenvolvimento sustentável. Revista de direito ambiental, n. 5, p. 53-55, jan./mar. 1997.

M ILARÉ, Edis. Direito do ambiente: a gestão ambiental em foco - doutrina, jurisprudência, glossário. 5. ed. São Paulo: Revista dos Tribunais, 2007.

PORTILHO, Fátima. Sustentabilidade ambiental, consumo e cidadania. São Paulo: Cortez, 2005.

SPINOLA, Ana Luiza. Consumo sustentável: 0 alto custo dos produtos que consumimos. Revista de Direito Ambiental, São Paulo, v. 6, n. 24, p. 209-216, out./dez. 2004.

SODRÉ, Marcelo Gomes. Padrões de consumo e meio ambiente. Revista de Direito do Consumidor, São Paulo, n. 31, p. 25-35, jul./set. 1999.

TRIGUEIRO, André. Mundo sustentável. São Paulo: Globo, 2005. 